\title{
Allelopathic Potential of Rice Residues of Selected Rice Varieties (Oryza sativa L.) Against Echinochloa crus-galli
}

\author{
A.S. Ranagalage, T.S.D. Jayakody and D.L. Wathugala* \\ Department of Crop Science, Faculty of Agriculture, University of Ruhuna, Mapalana, Kamburupitiya, \\ Sri Lanka
}

Date Received: 05-02-2014 Date Accepted: 03-07-2014

\begin{abstract}
Selection of rice varieties with greater allelopathic potential can be used as a tool in sustainable weed management. Exploitation and implementation of this technology in weed management has been considered as ecologically sound, resource conserving and economically viable method. The objective of this study was to assess the allelopathic traits of rice residues of selected rice cultivars $(\mathrm{Bg} \mathrm{359}$, $\mathrm{Ld}$ 365, Bg 407, At 401, Bg 358, At 362, At 402, Bg 450, Bg 300, Herathbanda and Handiran) to suppress barnyard grass (Echinochloa crus-galli) seed germination, growth and development which is one of the most destructive weeds in Sri Lankan paddy ecosystem. Completely Randomised Design was used with three replicates for each cultivar. According to the research findings, significant differences $(\mathrm{p} \leq 0.05)$ were observed among cultivars and amount of residue mixed with sand (2, 4, $6 \mathrm{~g}$ of ground residue per $500 \mathrm{~g}$ of sand) in terms of barnyard grass plant height, number of leaves, germination and total dry weight. Among those measured variables germination and dry matter accumulation of barnyard grass showed significant reduction when increasing amount of rice residues. Among different cultivars used Ld 365 showed the highest inhibition \% for all above measured variables and the lowest was the Herathbanda. As an example the inhibition percentages of plant height, seed germination and shoot dry weight of barnyard grass grown in $6 \mathrm{~g}$ of Ld 365 rice residue mixture were $72.7 \%, 74.2 \%$ and $82.6 \%$ respectively. In contrast, residues of rice variety Herathbanda caused 36.6\%, 37.9\% and 40.5\% inhibition respectively for above mentioned parameters. When comparing three levels of rice residue mixture suppression ability of barnyard grass seed germination was increased. Therefore, it could be suggested that the allelopathic potential of rice residue significantly changes with cultivar and amount of residue incorporated with soil. Knowledge of rice allelophathic properties of rice residue will offer several possibilities for ecological management of weeds in paddy fields in Sri Lanka.
\end{abstract}

Keywords: allelopathy, Echinocloa crus-galli, inhibition, Oryza sativa

\footnotetext{
*Correspondence: lakmini077@yahoo.com

Tel: +94718265218

ISSN 2235-9370 Print/ISSN 2235-9362 Online @ University of Sri Jayewardenepura

24
} 


\section{Introduction}

Rice is the dietary staple in Sri Lanka, and is cultivated in almost all parts of the island. In Sri Lanka, paddy cultivation has been hardly threatened by number of factors and circumstances. Out of them severe weed infestation in paddy fields become critical and it adversely affect to the ultimate paddy yield and quality. Rice growing areas worldwide are also seriously affected by the presence of several weeds. Weeds are plant species that compete with the crop for resources, such as sunlight, space and nutrients. Weed control is as old practice as agriculture itself. It is the method of limiting weed infestation so that crops can be grown profitably. Therefore, the degree of weed control depends on costs/benefits and the resources available. Nowadays, herbicide-based weed management is the most popular method of weed control in rice. Although, herbicide use alleviates the weed problem it emerge the unrecoverable and inevitable hazards to the natural environment including flora, fauna and human being. At the present crisis is the any aspect concern in environmental point of view. Herbicides cause degradation of water resources, bad effects on human health, reduces biodiversity and ultimate itself coined for development of herbicides resistant species. Therefore, shifting to environmentally friendly weed management methods is important. Generally, it could be observed that although herbicide use has increased productivity, there are several weed problems that remain unsolved and for which other solutions need to be developed and implemented (Labrada, 1996).

Barnyard grass (Echinochloa crus-galli) is one of the greatest yield-limiting weeds in the irrigated rice systems of Sri Lanka. It is better adapted to grow under dry conditions rather than wet conditions. Now most paddy farmers practice direct seeding to minimise cost of production and due to water scarcity paddy fields are not frequently in flooded condition. These practices create good conditions to grow barnyard grass in the paddy field and this weed expect to become greater problem in future (Im et al., 1993).

At field conditions competition and allelopathy effects cannot be separated. Initially plant breeders pay their great attention to uplift competition component rather than allelophathy. However, these emphasise showed little success. Allelopathy is defined as the direct or indirect harmful or beneficial effects of one plant on another through the production of chemical compounds that escape into the environment (Rice, 1984). Chemicals released from plants and imposing allelopathic influences are termed allelochemicals. Allelochemicals can be present in several parts of plants including roots, rhizomes, leaves, stems, pollen, seeds and flowers. Allelochemicals are released into the environment by root exudation, leaching from aboveground parts and volatilization and/or by decomposition of plant material (Rice, 1984; Reigosa et al., 1999). This phenomenon could be an alternative weed control method.

A number of studies have been conducted to evaluate the allelopathic potential from rice germplasm and number of rice accessions having allopathic potential have been determined in different places (Fujii, 1992; Garrity et al., 1992; Lin et al., 1992; Dilday et al., 1994; Hassn et al., 1994; Chou, 1995, 1999; Olofsdotter et al., 1995; Chung et al., 1997; Ahn and Chung, 2000). As an example Dilday et al., (1998) identified 412 accessions having allelopathic potential against ducksalad (Heteranthera limosa (Sw.) Willd.), among 12,000 accessions that originated from 31 different countries. These studies showed allelopathic potential is widely present in rice germplasm. Further it is assumed that rice allelopathy might be polygenetically controlled because it shows a continuous variation in the germplasm (Kim and Shin, 2003). Moreover, allelopathic potential is often attributed to several 
inhibitors that are assumed to act in an additive or synergistic way rather than in an isolated way (Courtois and Olofsdotter, 1998). Allelopathic potential of rice residues has also been studied in several places (Chung et al., 2001a; 2001b; Chung et al., 2002) and several allelochemicals have also been extracted from rice residues. Rice (1984) and Putnam (1985) reported that allelochemicals are present in virtually all plant parts, i.e., leaves, fruit, stems, rhizomes and roots. According to Aldrich (1984), allelochemicals must be concentrated in the leaves, stem or roots rather than in the fruit or flowers.

According to the Moody (1995) the phytotoxic potential of crop residues could be exploited in handling various weeds in agro-ecosystem successfully. The use of rice germplasm that contains high allelophathic activity, combined with incorporating straw into the soil controlled Cyperus irria almost effective as tank mixture of proponil+bentzon (Lin et al., 1992). Khan and Vaishya (1992) reviewed that residues of Sarjoo-52 rice incorporated 5-6 cm deep at $5 \mathrm{t} /$ ha reduced the population and biomass of Echinochloa colona. Chung et al., (2001) evaluated the allelopathic potential of rice in the laboratory, greenhouse and in the field using extracts and residues, and concluded that genetic variation in allelopathic activity exists among cultivars. These results supported previous studies (Garrity et al., 1992; Dilday et al., 1994; Olofsdotter et al., 1995). Although allelopathic research has been conducted for several decades very limited knowledge is still available whereas, little information is available on the allelopathic potential of rice cultivar in Sri Lankan context. Therefore, the main purpose of this study was to assess the allelopathic potential of selected rice varieties grown by Sri Lankan farmers on barnyard grass seed germination and seedling growth.

\section{Materials and Methods}

Eleven rice varieties including 9 Sri Lankan improved (Bg 359, Ld 365, Bg 407, At 401, Bg 358, At 362, At 402, Bg 450 and Bg 300) and two traditional (Herathbanda and Handiran) rice cultivars were grown at the field. At the maturity stage plants were harvested. The harvested plants (leaves plus straw) were dried at room temperature. E. crus-galli was also separately grown in the field for seed collection. After maturation E. crus-galli seeds were collected and debris was removed from the seeds by flotation in distilled water, then dried seeds were stored at room temperature until used. The seeds were treated in $100 \% \mathrm{H}_{2} \mathrm{SO}_{4}$ for 10 minutes to break dormancy. These seeds were soaked in water for overnight and then treated with 1:10 (v/v) dilution of topsin for $10 \mathrm{~min}$ to prevent fungal contaminations.

Bioassay was conducted in a greenhouse with an average room temperature. Various amount of ground rice residue (2 $\mathrm{g}$ (T1), $4 \mathrm{~g}$ (T2) and $6 \mathrm{~g}$ (T3)) from each cultivar were mixed thoroughly with $500 \mathrm{~g}$ of silica sand in each pot. All pots were placed on a petridish to prevent the loss of water-soluble toxic substances (Chung and Miller, 1995). Plastic net was placed in the bottom of each pot to prevent the loss of sand through the holes in the bottom. 100 E. crus-galli seeds prepared as described earlier were placed uniformly about $1 \mathrm{~cm}$ deep in each pot after two weeks of residue incorporation. Seedling emergence was defined as the coleoptile protrusion through the soil surface and was measured each day for 20 days after seeding. Water was added to pretridishes placed to each pot to maintain adequate moisture. All plants were harvested 20 days after planting. All plants from each pot were measured for shoot length, number of leaves and the seedlings were dried at $65^{\circ} \mathrm{C}$ to measure dry weight. Control plants were grown in silica sand without residue. The percentage inhibition of each measured parameter was calculated using the following equation (Chung et al., 2001).

Inhibition percentage $(\%)=[($ control-rice cultivar $) /$ control $] \times 100$ 
The experimental design used for this study was completely randomized design and three replicates were used for each treatment. Analysis of variance was performed for all data using a general linear model procedure.

\section{Results and Discussion}

Considerably a large number of researches have been conducted in different countries in order to find out and assesses allelophethic potential of different rice cultivars to achieve sustainable rice farming with minimum use of synthetic herbicides. However, in Sri Lanka, less information is available on allelopathic potential of rice cultivars and their residues. On the other hand rice residue incorporation in to the paddy fields is very much common practice in Sri Lanka. Therefore, present study aimed to compare abilities of residues of different rice varieties to control barnyard grass. The barnyard grass seed germination, plant height, seedling dry weight and number of leaves affected by the different amount of residues of selected rice varieties are shown in Figure 1. Data showed marked differences in measured parameters of barnyard grass. The influence of the incorporation of rice residue into sand and the inhibition of growth and development of barnyard grass may be resulted by toxic compounds released from the residues or produced by microorganism activity during residue decomposition. Among all measured variables inhibition percentages of seed germination and dry matter accumulation of barnyard grass showed significant reduction when increasing amount of rice residue incorporated to the sand to prepare residue mixture. That means concentration of allelochemicals release when decomposing residues have also been increased with the increase of amount of residues. Previous experiments reported the extraction of potential allelochemicals from soils incorporated with rice residue as well as residue aqueous extracts. As an example Chung et al. (2001a) has extracted 9 known allelochemicals and their mixtures from rice straw extracts by high performance liquid chromatography (HPLC) analysis. When susceptible plants are exposed to allelochemicals, germination, growth and development may be affected. The most reported gross morphological effects on plants by allelochemicals are retarded seed germination, effects on coleoptile elongation and on radicle, shoot and root development (Kruse et al,. 2000). Weir et al,. (2004) declared that inhibition of photosynthetic rate, interruption of respiration; ATP synthesis and amino acids metabolism were major physiological and biochemical mechanism that might be mediated by allelochemicals.

Inhibition $\%$ of number of leaves is lower than other measured characters for all tested varieties (Figure 1B). According to the results observed Ld 365 showed the highest inhibition \% for all above measured variables and the lowest was the Herathbanda (Figure 1). As far as Ld 365 short duration variety is concerned, it inhibit plant height, number of leaves, germination and dry weight by $72.2 \%$, $44.6 \%, 74.2 \%$ and $82.6 \%$ respectively when $6 \mathrm{~g}$ of rice residue incorporated to the mixture (Fig 1). These results indicate that residues of Ld 365 may have higher allelopathic potential against barnyard grass growth and development.

Dilday et al. (1994), Olofsdotter et al. (1995), Chung et al. (1997) and Ahn and Chung (2000) have conducted several experiments using rice residue extracts and rice residue incorporation with silica sand to compare allelopathic characteristics of various rice varieties and results showed that variations in allelopathic activity exist among tested rice varieties. A study conducted by Khan and Vaishya (1992) also reported the rice residue in soil inhibited the population and biomass of Echinochloa colona. Furthermore, Khanh et al., (2007) also reported residues of rice variety "Sarjoo 
52" blended into the soil (5-6 cm in depth, 5 tons $\mathrm{ha}^{-1}$ ) suppressed jungle rice (Echinochloa colona), monarch redstem (Ammania baccifera L.), Ammania multiflora Roxb., and gulf leaf flower (Phyllanthus fraternus Webster). In addition, several experiments also revealed that decomposing plant residues may either inhibit or stimulate plant growth, and that inhibition may be confined to a limited period, i.e., the most severe inhibition by plant residues occurs at the early stages of residue decomposition, whereas at later stages the inhibition declines while stimulation gradually emerges (An et al., 1998)

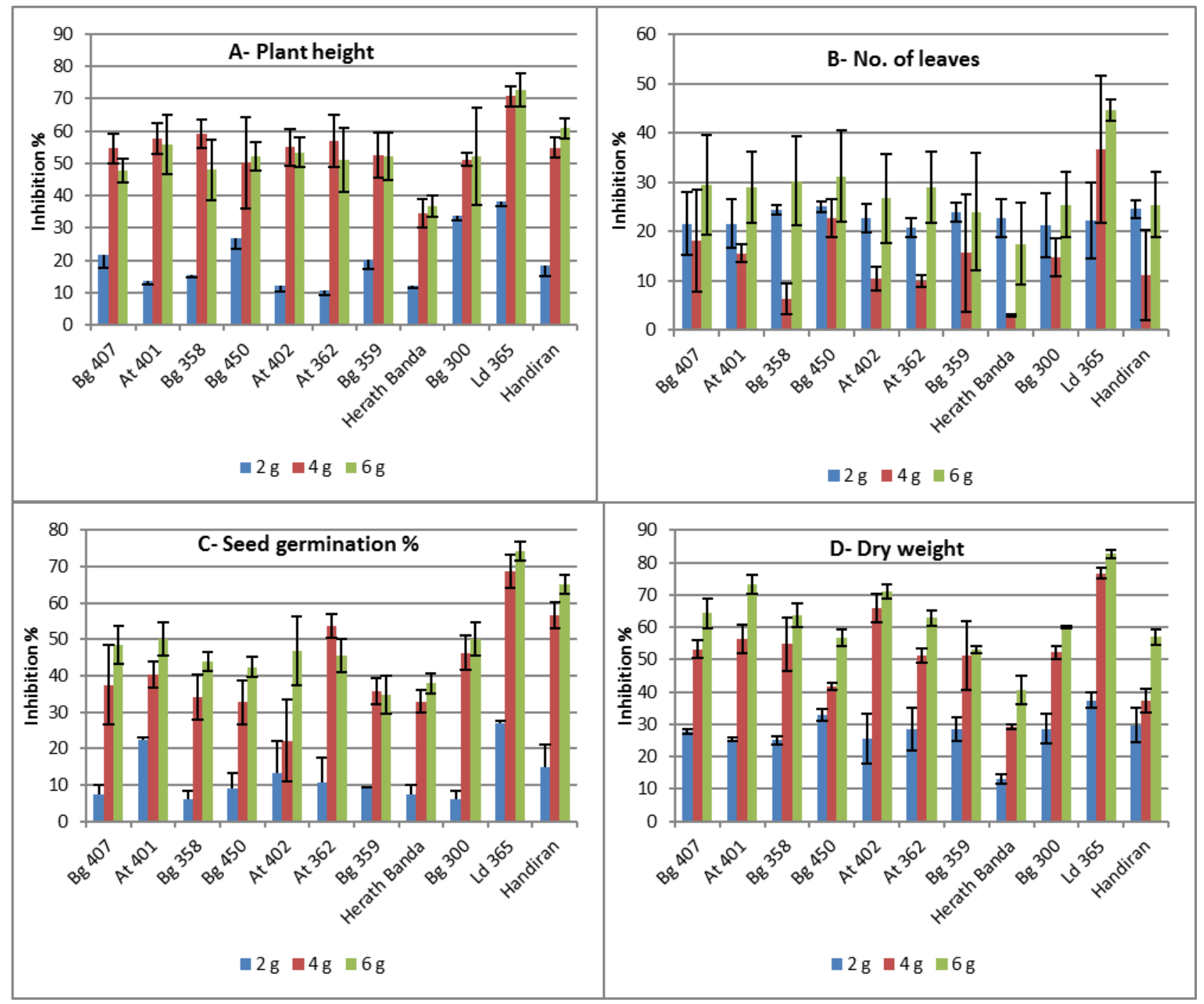

Figure 1: Comparison of inhibition percentages of barnyard grass plant height (A), number of leaves (B), seed germination (C) and dry weight (D) by different amount of rice residues of selected rice varieties incorporated with sand.

The difference in response was attributed to the genetic differences among the varieties, since the amounts of rice residues incorporated were the same. However, this allelopathic activity may be a result of higher concentrations of same chemical or a combination of different chemicals. Because, 
there are possibilities in decomposing rice residues may produce different amount of one or more allelopathic substances. Furthermore, the final outcome of allelopathic potential determined not only allelopathic substances itself, but also various other environmental and management practices are influenced. Therefore, further experiments in field conditions are needed to explore weed suppression ability of rice residues of selected rice varieties.

\section{Conclusion}

The objective of this study was to examine allelopathic potential of rice residue of different rice varieties. Results revealed that incorporating rice residue to paddy soil would be able to inhibit seed germination and growth of barnyard grass in some extend. Therefore, incorporation of residue to paddy soil is help to reduce competitiveness of barnyard grass and thereby reduced weed growth. Results also revealed that the allelopathic characters differ among tested rice varieties. On the basis of measured variables Ld 365 is the most allelopathic cultivar out of rice cultivars tested in this study. Traditional cultivar Herathbanda showed the lowest performance. Furthermore, suppression of seed germination and growth of barnyard grass was increased when increasing amount of rice residue incorporated with sand indicating the importance of studying weed suppressing ability of rice residues as it might reduce application of herbicides by the farmers. Isolation and identification of allelochemicals of selected varieties are also important for further analysis of allelopathic characters of rice.

\section{References}

Ahn, J.K. and Chung, I.M. 2000. Allelopathic potential of rice hulls on termination and seedling growth of barnyard grass. Agron. J., 92:1162-1167.

Aldrich, J.D. 1984. Weed-crop ecology: Principles and practices. Breton Publishers, pp.215-241.

An, M., Pratley, E. and Haig, T. 1998. Allelopathy from concept to reality environmental and analytical laboratories and farmer Center for Conservation Farming, Charles Sturt University, WaggaNSW 2656

Bhadoria, P.B.S. 2011. Allelopathy: A natural way towards weed management. American Journal of Experimental Agriculture, 1(1):7-20

Chou, C.H. 1995. Allelopathy and sustainable agriculture. in: Inderjit dakshini KMM and einhelling FA (Eds.), Allelopathy: organisms, process, and application. ACS Symposium Series 582. American Chemical Society, Washington, DC, pp. 211-223.

Chou, C.H. 1999. Role of allelopathy in plant biodiversity and sustainable agriculture. Crit. Rev. Plant Sci., 18:609-636.

Chung, I.M., Ahn, J.K. and Yun, S.J. 2001a. Assessment of allelopathic potential of barnyard grass (Echinochloa crus-galli) on rice (Oryza sativa L.) cultivars. Crop Protection, 20:921-928.

Chung, I.M., Ahn, J.K. and Yun, S.J. 2001b. Identification of allelopathic compounds from rice (Oryza sativa L.) straw and their biological activity. Canadian Journal of Plant Sciences, 81:815-819.

Chung, I.M., Kim, K.H., Ahn, J.K. and Ju, H.J. 1997. Allelopathic potential of rice varieties on Echinochloa crus-galli. Korean Journal of Weed Science, 17:52-58.

Chung, I.M., Kim, K.H., Ahn, J.K., Chun, S.C., Kim, C.S., Kim, J.T. and Kim, S.H. 2002. Screening of allelochemicals on barnyardgrass (Echinochloa crus-galli) and identification of potentially allelopathic compounds from rice (Oryza sativa) variety hull extracts. Crop Protection, 21:913920.

Chung, M. and Mille, D.A. 1995. Allelopathic influence of nine forage grass extracts on germination and seedling growth of alfalfa. Agron. J. Crop Res., 8:180-185. 
Courtois, B. and Olofsdotter, M. 1998. Incorporating the allelopathy trait in upland rice breeding programs. In: Olofsdotter M (ed.) Allelopathy in Rice. Manila, Philippines: Int. Rice Research Institute, pp. 57-68.

Dilday, R.H., Lin, J. and Yan, W. 1994. Identification of allelopathy in the USDA-ARS rice germplasm collection. Aust. J. Exp. Agric., 34:907-910.

Dilday, R.H., Yan, W.G., Moldenhauer, K.A.K. and Gravois, K.A. 1998. Allelopathic activity in rice for controlling major aquatic weeds. In Olofsdotter M. (ed.) Allelopathy in Rice. Manila, Philippines: Int. Rice Research Institute, pp.7-26.

Fujii, Y. 1992. The potential biological control of paddy weeds with allelopathy-allelopathic effect of some rice cultivars. Proceedings of the International Symposium on Biological Control and Integrated Management of Paddy and Aquatic Weeds, Tsukuba, Japan, pp.305-320.

Garrity, D.P., Movillon, M. and Moddy, K. 1992. Differential weed suppression ability in upland rice cultivars. Agron. J., 84:586-591.

Hassan, S.M., Aidy, I.R. and Bastawish, A.O. 1994. Allelopathic potential of rice varieties against major weeds in Egypt. In: Proceedings Weed Science Society of America Meeting, Seattle, Washington, USA, 63.

Im, I.B., Guh, O.J. and Oh, Y.J. 1993. Weed occurrence and competitive characteristic under different cultivation types of rice (Oryza sativa L.). 3. Difference in weed occurrence and rice growth under the competitive periods. Korean Journal of Weed Science, 13:114-121.

Khan, A.H. and Vaishya, R.D. 1992. Allelopathic effects of different crop residues on germination and growth of weeds. Proceedings of the First National Symposium on Allelopathy in Agroecosystems. Indian Society of Allelopathy, Haryana Agricultural University, Hisar, India, pp.50-60.

Khanh, T.D., Xuan, T.D. and Chung, I.M. 2007. Rice alleloapthy and the possibility for weeds management. Annals of Applied Biology, 151: 325-339.

Kim, K.U. and Shin, D.H. 2003. The importance of allelopathy in breeding new cultivars, In Weed management for developing countries. FAO Plant Production and Protection Paper No. 120 (Ed 1) ed. Labrada R., editor. (Rome: Food and Agriculture Org.) pp.195-210.

Kruse, M., Strandberg, M. and Strandberg, B. 2000. Ecological Effects of Allelopathic Plants: A review. National Environmental Research Institute, Silkeborg, Denmark. NERI Technical Report, pp.315: 66

Labrada, R. 1996. Weed management in rice. In Auld, B.A. \& Kim, K.U. eds. FAO Plant Production \& Protection Paper No. 139, FAO, Rome, pp.259-272

Lin, J., Smith Jr, R.J. and Dilday, R.H. 1992. Comparison of allelopathic rice and bensulfuron for aquatic weed control in rice. WSSA Abstr., pp. 33:170.

Moody, K. 1995. Sustainability in rice weed management. In: proceedings of the $15^{\text {th }}$ Asians-pacific weed science Conference, Tsukuba, Japan, pp.93-103.

Olofsdotter, M., Navarez, K. and Moody, K. 1995. Allelopathic potential in rice (Oryza sativa L.). Annals of Applied Biology, 127:543-560.

Putnam, A.R. 1985. Allelopathic research in agriculture: past highlights and potential. In: Thompson AC (Ed.), The Chemistry of Allelopathy. ACS Symposium Series. American Chemical Society, Washington, DC, pp.1-8.

Reigosa, M.J., Sanchez-Moreiras, A. and Gonzalez, L. 1999. Ecolophysiological approach in allelopathy. Crit. Rev. Plant Sci., 18: 577-608.

Rice, E.L. 1984. Allelopathy, 2nd Edition. Academic Press, Orlando, Florida. p422.

Weir, T.L., Park, S.W. and Vivanco, J.M. 2004. Biochemical and physiological mechanisms mediated by allelochemicals. Current opinion plant biology Journal, 9:195-203. 